\title{
Carnivoran ecomorphology: patterns below the family level
}

\author{
Lars Werdelin ${ }^{1, *} \&$ Gina D. Wesley-Hunt ${ }^{2}$
}

1) Department of Palaeobiology, Swedish Museum of Natural History, P.O. Box 50007, SE-104 05 Stockholm, Sweden ( ${ }^{*}$ corresponding author's e-mail: werdelin@nrm.se)

2) Biology Department, Montgomery College, 51 Mannakee St., Rockville, MD 20850, USA

Received 16 June 2013, final version received 19 Aug. 2013, accepted 21 Aug. 2013

Werdelin, L. \& Wesley-Hunt, G. D. 2014: Carnivoran ecomorphology: patterns below the family level. - Ann. Zool. Fennici 51: 259-268.

We studied the multivariate morphospace of a sample of 216 extant carnivoran species. Emphasis was placed on statistical patterns below the family level in the five largest families. Canidae and Felidae had small morphospaces, indicating low functional richness. Their species are highly non-randomly located in morphospace, hence low functional evenness. Clades at the subfamily level showed no patterning. Mustelidae had the greatest functional richness and were non-randomly distributed. There was partial subfamily patterning, with Lutrinae standing out as distinct. Herpestidae and Viverridae had intermediate functional richness and were randomly distributed in morphospace, showing high functional evenness. Subfamilial clades showed distinct patterning, especially in Viverridae, where the four subfamilies occupy distinct parts of morphospace.

\section{Introduction}

In a previous study, we discussed broad patterns of occupation of the morphospace of the carnivoran feeding apparatus (Werdelin \& WesleyHunt 2010). The focus in that report was at the family level and emphasized patterns of disparity (Foote 1994, Wesley-Hunt 2005) and biogeography. The results showed that phylogeny was a leading factor in structuring carnivoran morphospace and that biogeography, especially differences between the Old World and the New World, was a secondary but highly influential factor.

In a second contribution (Wesley-Hunt et al. 2010), we focused on two families, Herpestidae and Viverridae, and their comparative morpho- space occupation in Asia and Africa. Results of that study strongly suggested that there was a pattern of mutual exclusion as determined by prior occupation, such that neither family was able to dislodge the other from its ecomorphological spectrum, resulting in 'mirror-image' patterns of ecomorphology in Asia and Africa.

In this study, we move down a level in the taxonomic hierarchy and focus on subfamilies (or in cases where no subfamilies have been formally recognized, major clades) within the five largest extant carnivoran families (Canidae, Felidae, Herpestidae, Mustelidae, and Viverridae). Their morphospace occupation is shown in Fig. 1.

The major questions asked concern the structuring of morphospace at the subfamily level 


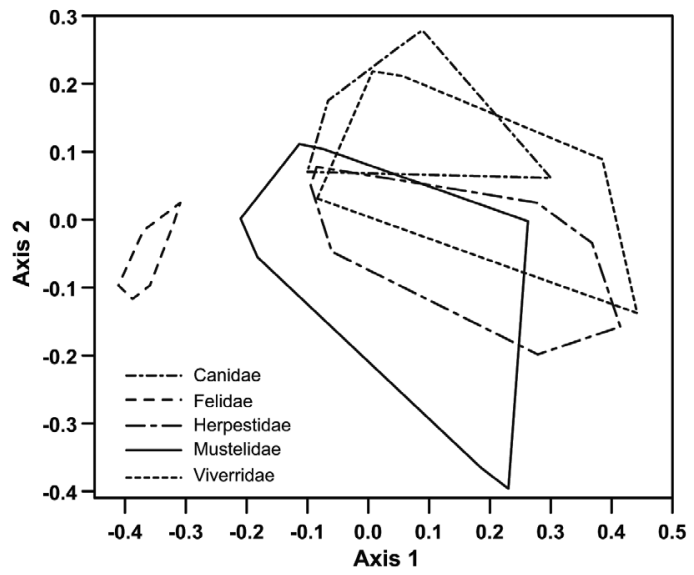

Fig. 1. Convex envelopes showing the morphospace occupation of the five families discussed in this paper in relation to each other. Note the contrast between Felidae and all other families along Axis 1 and the moderate structuring of Canidae, Herpestidae, Mustelidae, and Viverridae along Axis 2. The gap between Felidae and the other families remains if all carnivorans are included, though spotted and brown hyenas narrow it slightly.

or lower are: (1) Is morphospace still primarily structured by phylogeny or has this broken down? (2) Are the families similar in this respect or are there distinct differences?

At the same time that we ask these questions, we are introducing a new set of measures of morphospace occupation, taken from the ecological literature on ecosystem services. The main measures investigated herein are functional richness and functional evenness (Mason et al. 2005). The definition of functional richness is 'the amount of niche space filled by species in the community' (Mason et al. 2005). This was measured by taking the area of the convex hull enclosing all species in the space of the first two axes of a correspondence analysis (Benzécri \& Benzécri 1980, Cornwell et al. 2006). We are using only two axes from the 16 available, because all axes after these first two are dominated by the specific features of some taxon or small group of taxa and do not reflect the general patterns we are studying here.

Functional evenness is defined as the evenness of abundance distribution in filled niche space (Mason et al. 2005). For lack of abundance information, we adapted this definition to our purpose as the evenness of taxon distribution in filled niche space. Although not directly comparable to the measure obtained from the original definition, we suggest that our measure contains information regarding the grouping of taxa in niche space. In a global analysis such as that herein, this has interesting implications for the analysis of developmental pathways and speciation patterns, e.g., with regard to the evolution of hypercarnivory and its constraints (Van Valkenburgh 1991, Holliday \& Steppan 2004, Holliday 2010). In regional analyses, ecology and competition also become important for evenness.

\section{Material and methods}

The analysis on which this study is based was carried out on a set of 216 extant species, encompassing $85 \%$ of modern carnivoran species around the world (Wozencraft 1993). For each species, one specimen was selected to measure and code for 16 dental characters and body size, following the protocol detailed in Wesley-Hunt (2005). For character descriptions and complete data matrix, see Supplementary Information files in Werdelin and Lewis (2013). The specimen was selected after studying a larger sample to ensure that the data collected represents an average individual, with no morphologic abnormalities. Due to the nature of the characters, which were designed to allow the extremes of Carnivora to be compared (a polar bear to a weasel); the variation among individuals of a species would only rarely result in a slight difference in the code, and a concomitant minute difference in the position in morphospace. The specimens are housed in the following museums: Field Museum, Chicago; National Museum of Natural History, Smithsonian, Washington D.C.; American Museum of Natural History, New York; Museum für Naturkunde, Berlin; Museo Nacional De Ciencias Naturales, Madrid; Swedish Museum of Natural History, Stockholm.

The distribution of taxa in the space of the first two correspondence axes is presented herein with kernel plots. These provide a direct visual image of taxon distribution, showing hotspots where taxa are closer together in morphospace and gaps where there are no taxa present. Functional richness is derived from a nearest neigh- 
bor analysis (Davis 1986), which provides data on area, density, and other basic statistics of the point patterns. Functional evenness is calculated using several alternative methods including nearest neighbor analysis, and Ripley's $K$ (Ripley 1979). While these two analyses are related, they describe different aspects of evenness. Ripley's $K$ can describe point patterns at a variety of distance scales, such that clustering $v s$. regularity at both small and large scales can be distinguished (a point pattern may be evenly distributed at small scales, but aggregated at large ones). In nearest neighbor analysis, there is only one scale. Usage of both provides a better understanding of point patterns in the data.

All statistical calculations were carried out using PAST ver. 2.16 (Hammer \& Harper 2005). All graphs were made using Aabel ver. 3.0.5 (Gigawiz Ltd.).

\section{Results}

\section{Canidae}

In our previous work (Werdelin \& Wesley-Hunt 2010), we showed that disparity in Canidae was the second lowest among carnivoran families after Felidae. This is also the case with functional richness when measured as morphospace occupation. The area occupied by Canidae is just over $12 \%$ of the total morphospace area (Table 1). This occupation is very uneven, however, as can be seen from the kernel density plot (Fig. 2A). The majority of canids occupy a very small part of the total Canidae area, at the top of the second correspondence analysis axis.

Breaking Canidae down into four subclades (Canis group, South American foxes, true foxes, grey foxes) it can be seen (Fig. 2B) that all four

Table 1. Basic data on family and subfamily morphospace derived from nearest neighbor analysis of each group. Not all taxa belong to one of the listed subclades, hence the value of $N$ does not add up for all families. Also, note that the area percentages do not add up, because of the empty space between taxa in the morphospace plots. Subclade significances are not calculated due to the small sample sizes. Units are arbitrary and derived from the correspondence analysis of the entire carnivoran sample.

\begin{tabular}{|c|c|c|c|c|c|c|c|}
\hline $\begin{array}{l}\text { Family/ } \\
\text { Subclade }\end{array}$ & $n$ & Area & $\begin{array}{l}\text { Percentage } \\
\text { of total area }\end{array}$ & $\begin{array}{l}\text { Mean } \\
\text { density }\end{array}$ & $\begin{array}{c}\text { Mean } \\
\text { distance }\end{array}$ & $\begin{array}{l}\text { Expected } \\
\text { distance }\end{array}$ & $p$ (random) \\
\hline Canidae & 32 & 0.04883 & 12.2425 & 634.9 & 0.00530 & 0.01984 & $5.78 \mathrm{E}-15$ \\
\hline Vulpini & 11 & 0.01949 & 4.8871 & 564.3 & 0.01697 & & \\
\hline Vulpini excl. Otocyon & 10 & 0.00123 & 0.3075 & 8164.7 & 0.00185 & & \\
\hline South American foxes & 9 & 0.00570 & 1.4299 & 1578.1 & 0.00749 & & \\
\hline Canini & 9 & 0.00642 & 1.6093 & 1402.1 & 0.01293 & & \\
\hline Felidae & 35 & 0.00533 & 1.3375 & 6561.2 & 0.00486 & 0.00062 & 0.01585 \\
\hline Domestic cat & 5 & 0.00099 & 0.2494 & 5027.6 & 0.01124 & & \\
\hline Ocelot & 7 & 0.00194 & 0.4861 & 3610.3 & 0.00813 & & \\
\hline Panthera & 6 & 0.00102 & 0.2549 & 5901.7 & 0.00668 & & \\
\hline Leopard cat & 5 & 0.00073 & 0.1837 & 6824.3 & 0.00498 & & \\
\hline Mustelidae & 51 & 0.12819 & 32.1399 & 397.9 & 0.02336 & 0.02507 & 0.35133 \\
\hline Lutrinae & 13 & 0.01854 & 4.6476 & 701.3 & 0.02409 & & \\
\hline Martinae & 9 & 0.01678 & 4.2076 & 536.3 & 0.02773 & & \\
\hline Galictinae & 7 & 0.02341 & 5.8689 & 299.0 & 0.03460 & & \\
\hline Mustelinae & 15 & 0.01850 & 4.6371 & 811.0 & 0.02234 & & \\
\hline Herpestidae & 27 & 0.08003 & 20.0652 & 337.4 & 0.03099 & 0.02722 & 0.16899 \\
\hline Indian Herpestes & 8 & 0.00970 & 2.4315 & 824.9 & 0.01402 & & \\
\hline Galerella group & 10 & 0.04792 & 12.0138 & 208.7 & 0.03192 & & \\
\hline Helogale group & 8 & 0.01905 & 4.7760 & 420.0 & 0.02884 & & \\
\hline Viverridae & 23 & 0.09789 & 24.5426 & 235.0 & 0.03530 & 0.03262 & 0.43468 \\
\hline Paradoxurinae & 6 & 0.01044 & 2.6173 & 574.8 & 0.02204 & & \\
\hline Hemigalinae & 3 & 0.00444 & 1.1131 & 675.8 & 0.00967 & & \\
\hline Viverrinae & 5 & 0.00458 & 1.1487 & 1091.3 & 0.01908 & & \\
\hline Genettinae & 9 & 0.02166 & 5.4316 & 415.4 & 0.00789 & & \\
\hline All & 216 & 0.39885 & 100 & 541.6 & 0.01686 & 0.02149 & 1.47E-09 \\
\hline
\end{tabular}



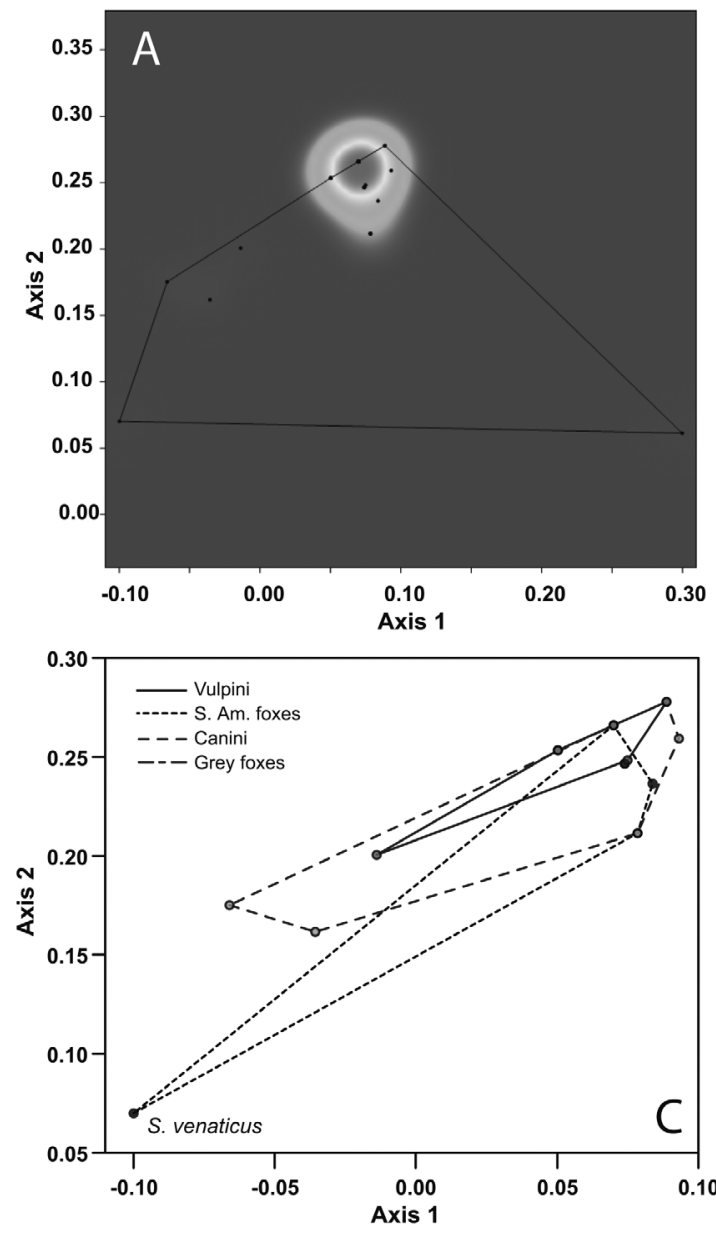

occur in this small region of the morphospace, with a few outliers, the most important of which are Otocyon megalotis, bat-eared fox, which as a feeder on social insects is more hypocarnivorous than any other canid, and the most hypercarnivorous canids, Speothos venaticus, bush dog, Lycaon pictus, African hunting dog, Cuon alpinus, dhole, and Vulpes lagopus, Arctic fox. All other canids, even the grey wolf, Canis lupus, fall within the restricted canid core region.

Taxon distribution in the canid morphospace is clearly not random, as indicated by the nearest neighbor analysis (Table 1). This is corroborated by Ripley's $K$ analysis (not shown) with a distinct first-order pattern dominated by the concentration of taxa highlighted in the kernel plot, where taxa are more closely associated than would be expected from complete spatial randomness (CSR). Thus, functional evenness is

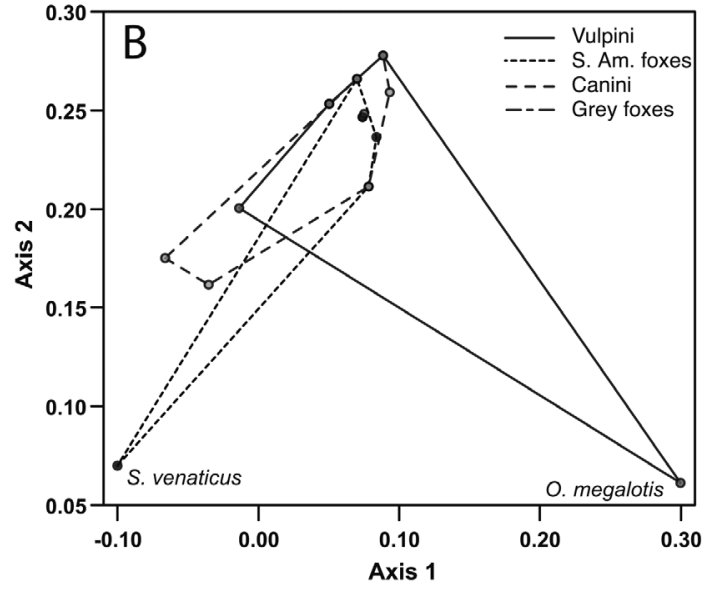

Fig. 2. Analysis of canid morphospace. (A) Kernel density plot showing a hotspot at the top of the figure where the majority of canid species are congregated. (B) Canid morphospace broken down by subclade (tribe). The outliers $O$. megalotis and $S$. venaticus are noted. (C) Same as the previous figure but with $O$. megalotis removed. The superposition of all subclades is marked.

low. Interestingly, despite this non-random pattern, overlap between the major canid clades is extensive, and if the most extreme outliers are removed it is almost complete (Fig. 2C). This suggests strong constraints on the morphology of the canid feeding apparatus. Such constraints are surprising and apparently confined to the extant subfamily Caninae, as the extinct canid subfamilies Borophaginae and Hesperocyoninae clearly show a greater range of ecomorphology than seen among canids today (Wang 1994, Wang et al. 1999). Preliminary exploration of fossil Caninae does not change this pattern. Much further investigation will be needed to identify the causes of this restricted functional richness of Caninae.

Functional richness is about even in the three major subclades; the grey fox clade includes only two species, so the measure of functional richness used is undefined. 


\section{Felidae}

Felidae is the family with the smallest morphospace occupation, i.e., with the smallest contribution to functional richness. Felid morphospace occupation is only $1.3 \%$ of the total carnivoran morphospace (Table 1). Since there are many species of felid, mean density within this space is extremely high, in fact more than an order of magnitude greater than that of any other family. Several studies have discussed this phenomenon, mainly focusing on its origin in constraints on hypercarnivore morphology (Holliday 2010) and on how so many felids can coexist (Kiltie 1984, Dayan et al. 1990).

The kernel plot (Fig. 3A) shows that there are some hotspots near the center of felid morphospace. Since felids are so similar to one another, and so difficult to separate on features studied herein, each of these hotspots, though all appear to be single points, is the result of several superimposed taxa that are identical for all variables included. In fact, both hotspots include members of five of the eight major clades of Felidae (Fig. 3A; Johnson et al. 2006, Werdelin et al. 2010). This type of pattern essentially renders Ripley's $K$ analysis (not shown) uninterpretable, but the nearest neighbor analysis suggests that there is some attraction between points, though the pattern is not highly significant. Functional evenness within Felidae is thus moot.

Breakdown into the major subclades (Fig. 3B) shows there to be substantial overlap, though some subclades (e.g. the Panthera clade) are found only in circumscribed parts of the morphospace. However, the overall morphospace is so small that differences within it are minute. It should be noted that including the extinct sabertooth cats, which some respects are a very different morphotype from extant Felidae, increases the size of the felid morphospace in this analysis only marginally, as in terms of their feeding apparatus they are largely similar to extant felids, only in some cases more extreme. The reasons for this are well explained by the analysis of Holliday (2010).

\section{Mustelidae}

Mustelidae is the most speciose family of Car-
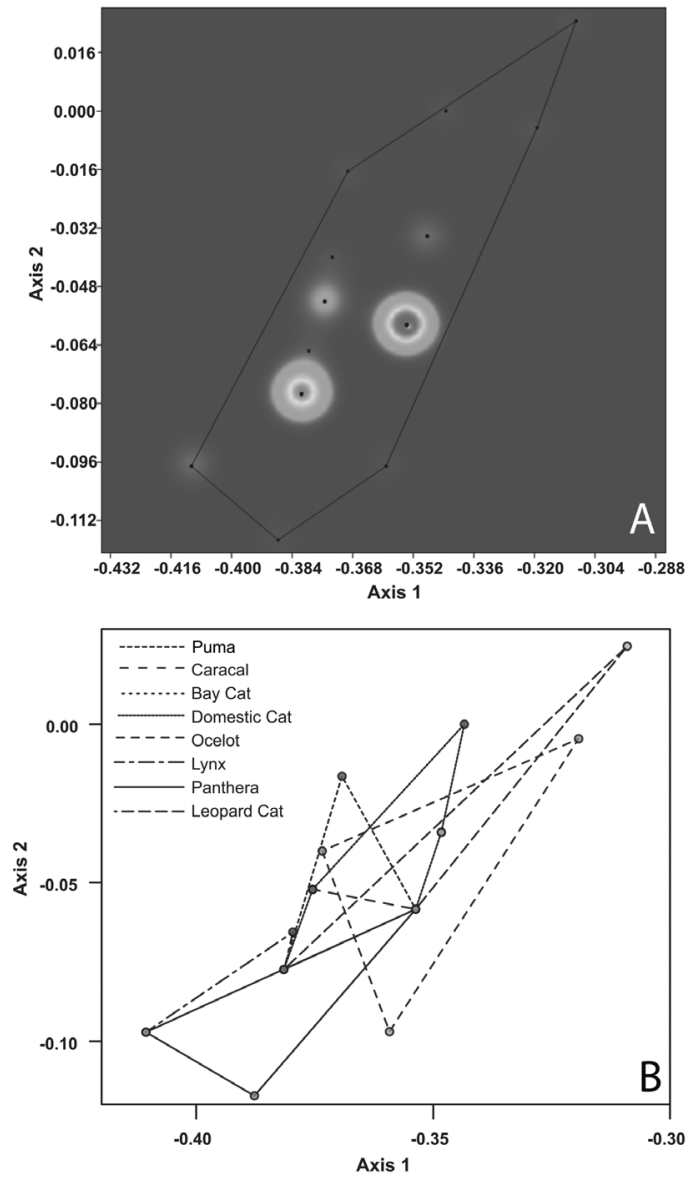

Fig. 3. Analysis of felid morphospace. (A) Kernel density plot with two hotspots in the center of the distribution. Each of these represents several superimposed taxa. (B) Felid morphospace broken down by subclade. Clade names after Johnson et al. (2006). Note the Panthera subclade at the bottom left.

nivora and its morphospace occupation is also the greatest at just over $32 \%$ of the total carnivoran morphospace. However, the large number of species means that mean taxon density is higher than in the Herpestidae and Viverridae, though much lower than in Canidae and Felidae. Although the kernel plot (Fig. 4A) shows them to have a concentration at the upper left (relatively premolar-dominated hypercarnivore) part of their morphospace, coverage across the mustelid morphospace is relatively even as compared with that of, e.g., Canidae.

Ripley's $K$ analysis shows a unique pattern (Fig. 4B), where there is significant attraction at all but the very shortest distances, but a strong 

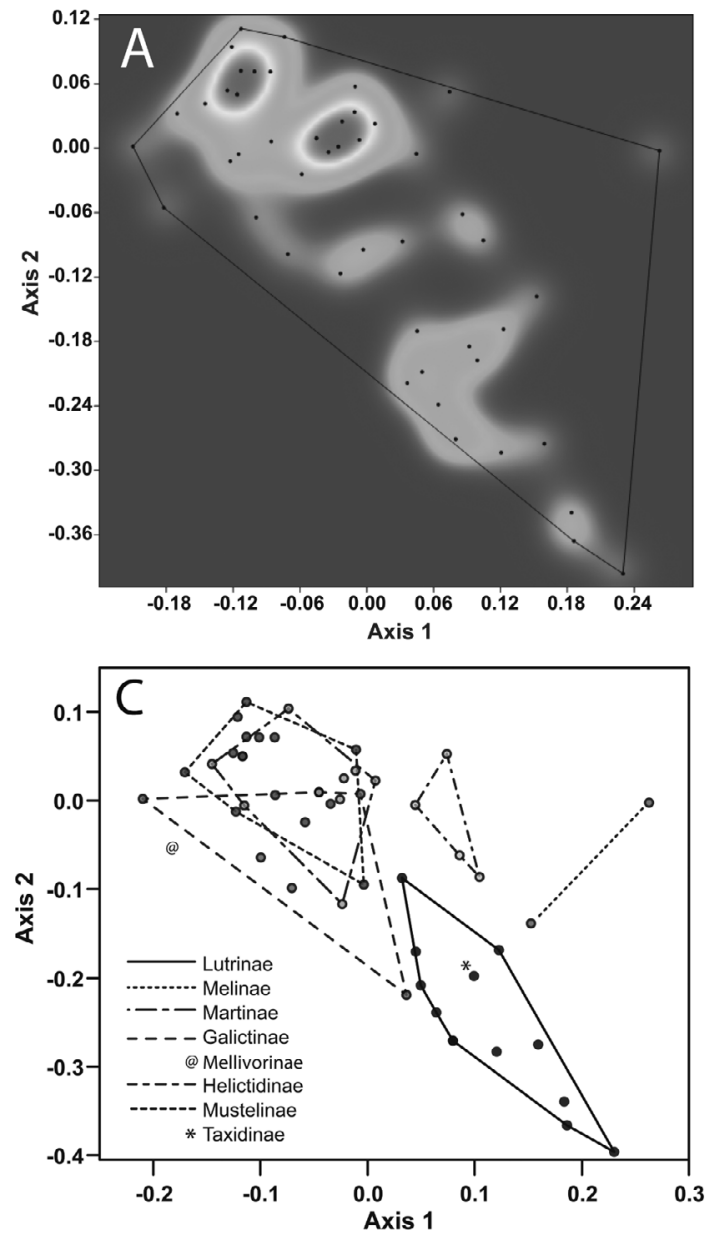

peak at a distance of about 0.125 . Inspection of the pattern of distribution of mustelid subfamilies (Fig. 4C) shows that the upper left concentrations correspond, with some scatter, to Mustelinae (weasels and kin; uppermost left), Martinae (martens and fishers; next to it), and Lutrinae (otters; bottom right). Thus, functional evenness is low, but the reasons for it are unclear.

The subfamily distribution is interesting in other respects as well. Although there is a major concentration at the upper left, with Mustelinae, Martinae, and Galictinae (grisons and kin), other subfamilies lie entirely outside this concentration, and also separately from each other. This includes Lutrinae, Helictidinae (ferret-badgers), Melinae (true badgers), and Mellivorinae (honey badgers). This pattern of subfamily distribution will require further analyses to understand, but these lie beyond the scope of this preliminary paper.

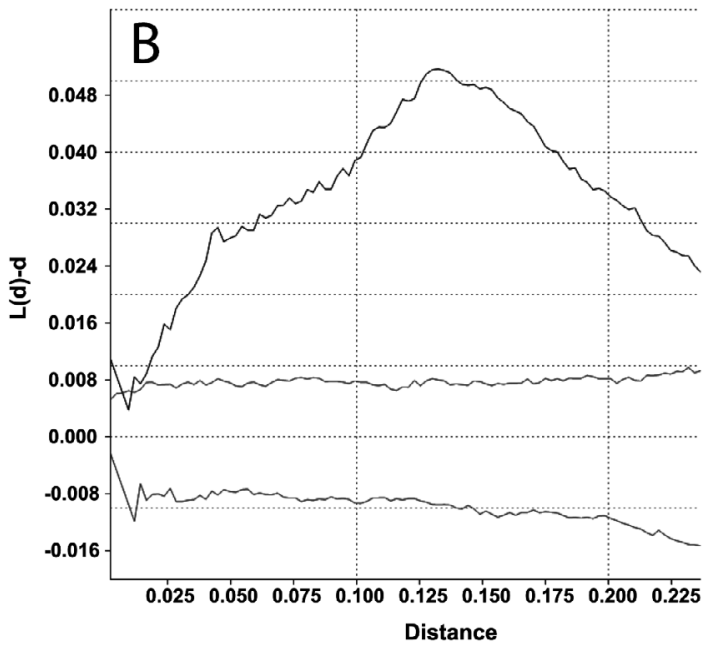

Fig. 4. Analysis of mustelid morphospace. (A) Kernel density plot showing two hotspots to the upper left, composed of the Mustela and Martes species groups. (B) Ripley's K analysis of species distribution. The grey lines represent the 95\% confidence interval of complete spatial randomness (CSR). The dark line shows that mustelid distribution lies above the confidence envelope for all distances, indicating that points (species) show greater attraction than expected by chance. (C) Mustelid morphospace broken down by subfamily. Note especially the distinct lutrine morphospace at the bottom right.

\section{Herpestidae}

We have previously discussed some interesting biogeographic patterns with regard to Herpestidae and Viverridae (Wesley-Hunt et al. 2010). These form a backdrop to the present discussion of subclade patterns in these families. Herpestidae occupy about $20 \%$ of the total carnivoran morphospace, with a taxon density that is intermediate between Mustelidae and Viverridae. The kernel plot shows that there are two hotspots, one closer to the hypercarnivore end of the herpestid morphospace and a lesser one closer to the hypocarnivore end (Fig. 5A). Despite these hotspots, Ripley's $K$ indicates no dominant firstorder effects and suggests that spatial distribution is near to CSR over all distances (Fig. 5B). Functional richness is thus substantial and evenness high in this family. 

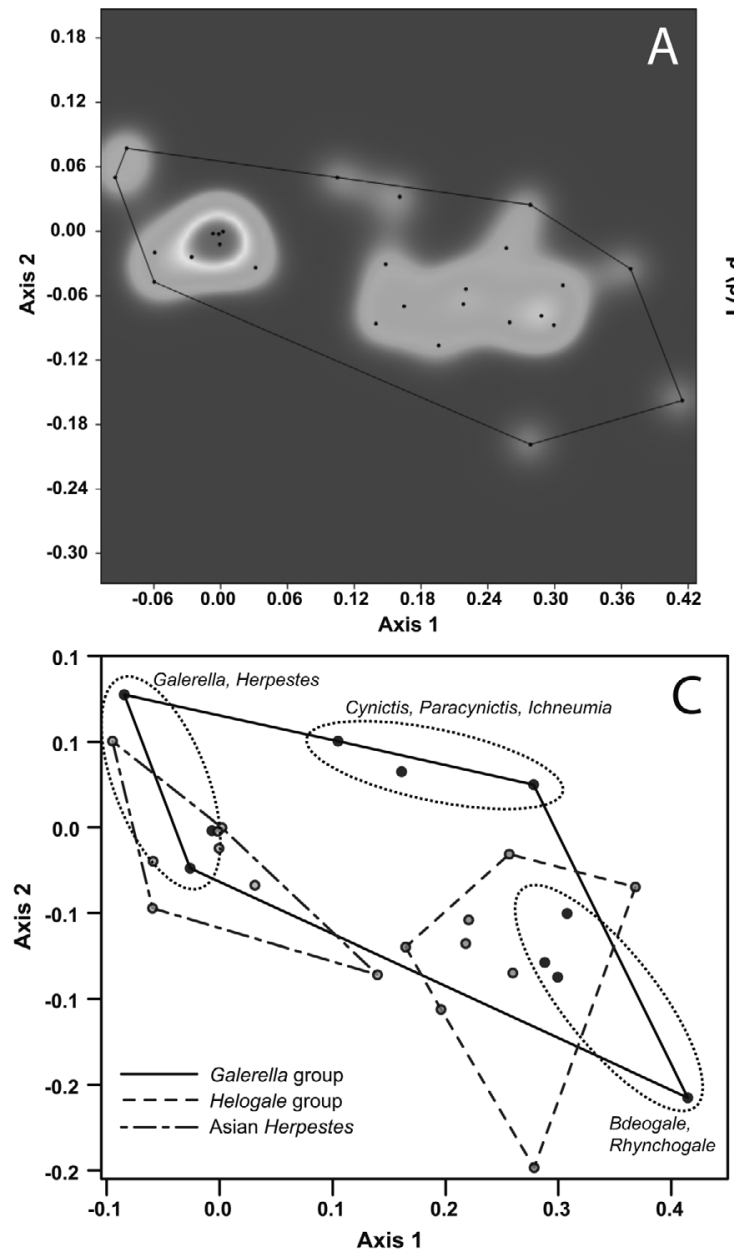

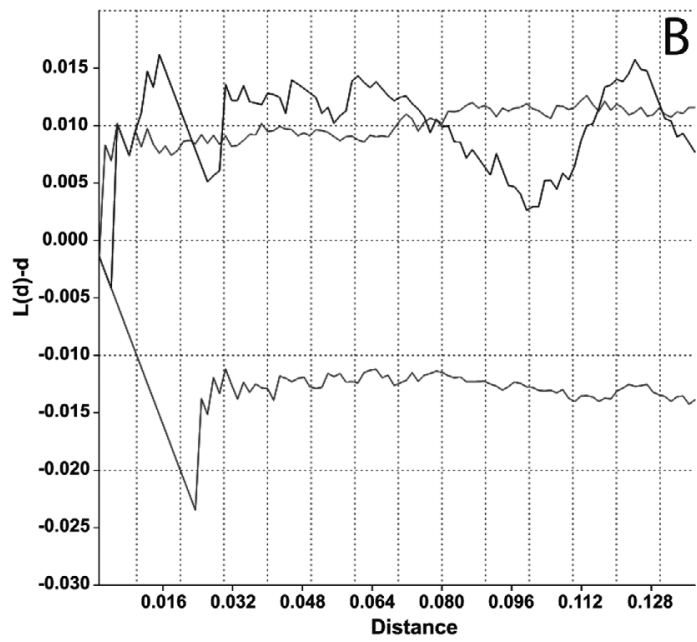

Fig. 5. Analysis of herpestid morphospace. (A) Kernel density plot showing one hotspot to the left, composed mainly of species of the genus Herpestes. (B) Ripley's $K$ analysis of species distribution. The viverrid line hovers at the upper end of the $95 \%$ confidence envelope, suggesting spatial randomness. (C) Herpestid morphospace broken down by subclade. Note separation of Helogale group and Asian Herpestes group, as well as the three distinct subgroups within the Galerella group.
Herpestidae includes three major subclades (Patou et al. 2009), though none of these have been formally named or assigned a rank. These subclades are: (1) the 'Helogale group', including the genera Helogale, Crossarchus, Suricata, Mungos, and Liberiictis; (2) the 'Galerella group', including the genera Galerella, Herpestes (H. ichneumon only), Ichneumia, Bdeogale, Rhynchogale, Cynictis, and Paracynictis; (3) the 'Indian herpestid group', including the genus Urva (previously placed in Herpestes). Of these three, the first two are endemic to Africa and the third endemic to southern and southeastern Asia.

It is noteworthy that the Helogale group and the Indian herpestid group occupy distinct parts of the morphospace, while the Galerella group overlaps with both (Fig. 5C). This, of course, relates to the biogeographic pattern between
African and Asian Herpestidae and Viverridae discussed elsewhere (Wesley-Hunt et al. 2010) and we refer to that discussion. Of considerable interest in the context of subclade differentiation is, however, the pattern of morphospace occupation within the Galerella group. This group can be conveniently subdivided into a cluster to the lower right, a cluster in the middle top, and a cluster to the left (Fig. 5C). These clusters all include taxa that are closely related according to the latest phylogenetic information (Patou et al. 2009). The lower right cluster includes species of the genera Bdeogale and Rhynchogale that form a monophyletic clade in Patou et al. (2009). The middle top cluster includes the genera (all monotypic) Cynictis, Paracynictis, and Ichneumia, which form a stem lineage to the Bdeogale/Rhynchogale clade. The cluster on the left includes 

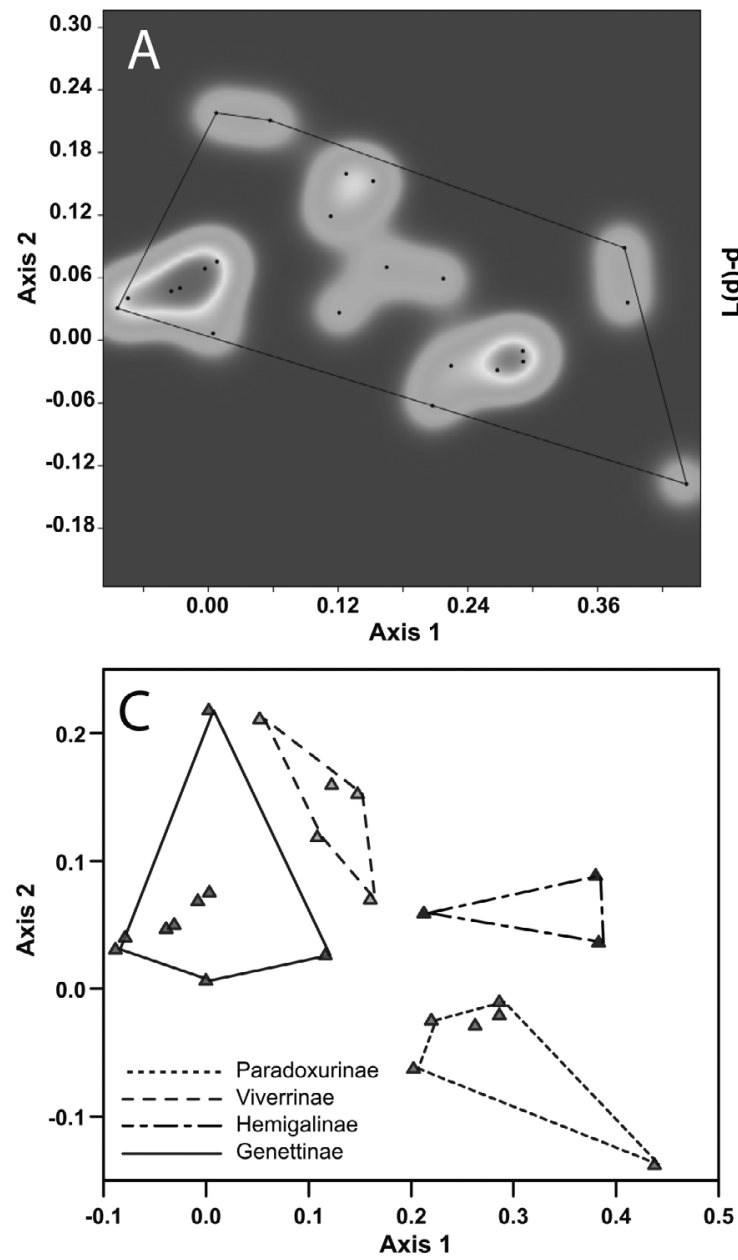

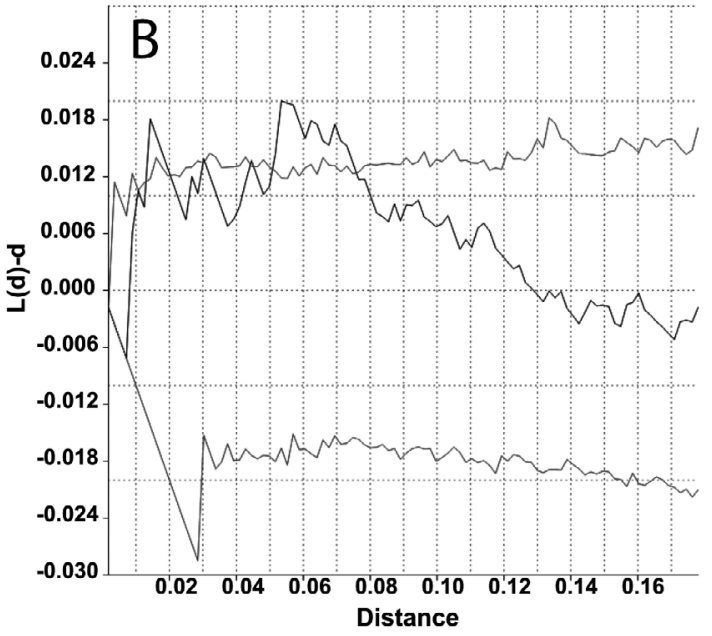

Fig. 6. Analysis of viverrid morphospace. (A) Kernel density plot showing two hotspots; the left one is composed mainly of the genus Genetta while the right is a mixed assemblage. (B) Ripley's $K$ analysis of species distribution. At shorter distances (left) the viverrid line lies around the upper end of the $95 \%$ confidence envelope, suggesting spatial randomness at these distances. At longer distances the viverrid line lies well within the $95 \%$ envelope indicating complete spatial randomness. (C) Viverrid morphospace broken down by subfamily. Note the complete separation of these clades in morphospace. species of the genera Galerella and Herpestes, which are often considered congeneric.

It is tempting to suggest that the distinct phylogenetic patterning of the Galerella-group morphospace is due to recent divergences and insufficient time for morphological differentiation. However, the analyses of Patou et al. (2009) suggest quite the opposite. The divergences within this clade go back well into the Miocene and the reasons for the apparent morphological conservatism of the feeding apparatus must be sought elsewhere, possibly in an ecological conservatism characteristic of the family.

Finally, it is noteworthy that neither the patterns reported here nor the fossil record show any major gaps indicative of extinctions of ecomorphologically aberrant herpestids. The family appears to always have consisted of small spe- cies with constrained ecomorphologies. The closely related Eupleridae (Madagascar 'herpestids') are another matter. These are not treated here, but may be seen in Werdelin and WesleyHunt (2010) to have been ecomorphologically quite different in many respects from Herpestidae, suggesting that their migration to Madagascar effected an ecological release that led to ecomorphological differentiation.

\section{Viverridae}

Viverridae has the second highest morphospace occupation of all families ( $24 \%$ of total carnivoran morphospace) (Table 1), but density is the lowest among all five large carnivoran families. The kernel plot (Fig. 6A) shows that Viverridae 
are distributed fairly evenly across this area, with the only standout hotspot being at the far left, which is dominated by the speciose genus Genetta (Gaubert et al. 2005). Ripley's $K$ analysis (Fig. 6B) shows the distribution of viverrid species to be within CSR for nearly all distances. Thus, in both richness and evenness viverrids are closely similar to herpestids.

The most interesting aspect of the Viverridae morphospace appears in the lack of overlap between any of the viverrid subfamilies (Fig. 6C). The morphospace is broadly separated into a gradient from Genettinae (most hypercarnivorous) over Viverrinae, Paradoxurinae, and Hemigalinae (most hypocarnivorous). Of these, the Hemigalinae have the smallest morphospace and Genettinae the largest (Table 1).

The low species density in viverrid morphospace, as well as, to some extent, the lack of overlap between subfamilies, which is unique to Viverridae, suggests that there may be extinct viverrids that filled out parts of the morphospace. Both the African and Eurasian fossil records corroborate this, recording the presence of several extinct viverrids that differ in size and morphology from extant ones (Kretzoi \& Fejfar 1982, Werdelin \& Lewis 2005). The phylogenetic placement of these taxa is not certain, though they appear to be closest to Viverrinae. The analyses of past African carnivore morphospace (Werdelin \& Lewis 2013) suggest, but do not prove, because of the differing contents of those analyses and the present ones, that extinct species extend the Viverrinae morphospace towards the hypocarnivorous end of the distribution.

\section{Discussion}

The two main questions posed about morphospace occupation at the subfamily level or lower have been answered by the analyses carried out here. Is morphospace still primarily structured by phylogeny or has this broken down, and are the families similar in this respect or are there distinct differences? There is subfamily structuring but it varies greatly from family to family. In Viverridae subfamily phylogenetic structuring is extensive. In Mustelidae and Herpestidae, there is some subfamily structuring - in Herpestidae there is also some distinct structuring below subfamily, but not in all clades. In Canidae and Felidae, however, there is little or no subfamily (subclade) structuring. This may be because these families are actually already subfamilies, being remnants of once more extensive radiations, where one or several subfamilies have become extinct. The fossil records of the other three clades are not extensive enough to show whether a similar pattern applies to them, although the clade ages suggested for Mustelidae (Koepfli et al. 2008) indicates that it might not be the case there.

This contribution is a very preliminary accounting of intra-familial patterns of morphospace occupation in extant Carnivora. It only considers phylogeny in a very crude way. This will be considered in more detail in future studies. Phylogeny, which is the dominant pattern in carnivoran morphospace mapping must be accounted for if the ecological pattern is to be identified.

In terms of functional richness and functional evenness, the most significant findings are that Canidae and Felidae have very low functional richness, together accounting for less than $15 \%$ of the total carnivoran functional richness. Both families show low functional evenness. Mustelidae shows the greatest functional richness but low evenness, with a pattern dominated by a dichotomy of small, relatively hypercarnivorous species (martens, weasels) and larger relatively hypocarnivorous species (otters, badgers). Herpestidae and Viverridae have intermediate functional richness and both have high functional evenness, with the species within each clade distributed statistically randomly across each family's morphospace.

In conclusion, although Canidae and Felidae (and Hyaenidae) tend to garner most of the attention in discussions of carnivoran ecology and conservation, if the goal of conservation is to preserve the maximum amount of functional richness, much more attention should be paid to the small carnivorans, which make up the vast majority of carnivoran morphospace and hence the functional richness of the order.

\section{Acknowledgements}

We thank the staff at the Museum für Naturkunde, Berlin; 
Museo Nacional De Ciencias Naturales, Madrid, National Museum of Natural History, Smithsonian, Washington D.C., American Museum of Natural History, New York, Field Museum of Natural History, Chicago, and Swedish Museum of Natural History, Stockholm, for their time and assistance. Suvi Viranta and an anonymous reviewer provided valuable comments on the manuscript. This work was funded by grants to LW from the Swedish Research Council.

\section{References}

Benzécri, J.-P. \& Benzécri, F. 1980: Pratique de l'analyse des données. 1. Analyse des correspondances. Exposé élémentaire. - Dunod, Paris.

Cornwell, W. K., Schwilk, D. W. \& Ackerly, D. D. 2006: A trait-based test for habitat filtering: Convex hull volume. - Ecology 87: 1465-1471.

Davis, J. C. 1986: Statistics and data analysis in geology. John Wiley \& Sons, New York.

Dayan, T., Simberloff, D., Tchernov, E. \& Yom-Tov, Y. 1990: Feline canines: Community-wide character displacement among the small cats of Israel. - American Naturalist 136: 39-60.

Foote, M. 1994: Morphological disparity in OrdovicianDevonian crinoids and the early saturation of morphological space. - Paleobiology 20: 320-344.

Gaubert, P., Taylor, P. J. \& Veron, G. 2005: Integrative taxonomy and phylogenetic systematics of the genets (Carnivora, Viverridae, Genetta): A new classification of the most speciose carnivoran genus in Africa. - In: Huber, B. A., Sinclair, B. J. \& Lampe, K.-H. (eds.), African biodiversity. Molecules, organisms, ecosystems: 371-383. Springer, New York.

Hammer, Ø. \& Harper, D. A. T. 2005: Past, version 1.33. University of Oslo.

Holliday, J. A. 2010: Evolution in Carnivora: Identifying a morphological bias. - In: Goswami, A. \& Friscia, A. (eds.), Carnivoran evolution. New views on phylogeny, form, and function: 189-224. Cambridge University Press, Cambridge.

Holliday, J. A. \& Steppan, S. J. 2004: Evolution of hypercarnivory: The effect of specialization on morphological and taxonomic diversity. - Paleobiology 30: 108-128.

Johnson, W. E., Eizirik, E., Pecon-Slattery, J., Murphy, W. J., Antunes, A., Teeling, E. \& O’Brien, S. J. 2006: The late Miocene radiation of modern Felidae: a genetic assessment. - Science 311: 73-77.

Kiltie, R. A. 1984: Size ratios in sympatric neotropical cats. - Oecologia 61: 411-416.

Koepfli, K. P., Deere, K. A., Slater, G. J., Begg, C., Begg, K., Grassman, L., Lucherini, M., Veron, G. \& Wayne, R. K. 2008: Multigene phylogeny of the Mustelidae: Resolving relationships, tempo and biogeographic history of a mammalian adaptive radiation. - BMC Biology 6: 10 .
Kretzoi, M. \& Fejfar, O. 1982: Viverriden (Carnivora, Mammalia) im europäischen Altpleistozän. - Zeitschrift für geologische Wissenschaften 10: 979-995.

Mason, N. W. H., Mouillot, D., Lee, W. G. \& Wilson, J. B. 2005: Functional richness, functional evenness and functional divergence: The primary components of functional diversity. - Oikos 111: 112-118.

Patou, M.-L., Mclenachan, P. A., Morley, C. G., Couloux, A., Jennings, A. P. \& Veron, G. 2009: Molecular phylogeny of the Herpestidae (Mammalia, Carnivora) with a special emphasis on the Asian Herpestes. - Molecular Phylogenetics and Evolution 53: 69-80.

Ripley, B. D. 1979: Tests of 'randomness' for spatial point patterns. - Journal of the Royal Statistical Society B 41: 368-374.

Van Valkenburgh, B. 1991: Iterative evolution of hypercarnivory in canids (Mammalia: Carnivora): evolutionary interactions among sympatric predators. - Paleobiology 17: 340-362.

Wang, X. 1994: Phylogenetic systematics of the Hesperocyoninae (Carnivora: Canidae). - Bulletin of the American Museum of Natural History 221: 1-207.

Wang, X., Tedford, R. H. \& Taylor, B. E. 1999: Phylogenetic systematics of the Borophaginae (Carnivora: Canidae). - Bulletin of the American Museum of Natural History 243: 1-391.

Werdelin, L. \& Lewis, M. E. 2005: Plio-Pleistocene Carnivora of eastern Africa: Species richness and turnover patterns. - Zoological Journal of the Linnean Society 144: 121-144.

Werdelin, L. \& Wesley-Hunt, G. D. 2010: The biogeography of carnivore ecomorphology. - In: Goswami, A. \& Friscia, A. (eds.), Carnivoran evolution: New views on phylogeny, form, and function: 225-245. Cambridge University Press, Cambridge.

Werdelin, L. \& Lewis, M. E. 2013: Temporal changes in functional richness and evenness in the eastern African Plio-Pleistocene carnivoran guild. - PLOS One 8(3): e57944, doi:10.1371/journal.pone.0057944.

Werdelin, L., Yamaguchi, N., Johnson, W. E. \& O'Brien, S. J. 2010: Phylogeny and evolution of cats. - In: Macdonald, D. M. \& Loveridge, A. (eds.), Biology and conservation of wild felids: 59-82. Oxford University Press, Oxford.

Wesley-Hunt, G. D. 2005: The morphological diversification of carnivores in North America. - Paleobiology 31: $35-55$.

Wesley-Hunt, G. D., Dehghani, R. \& Werdelin, L. 2010: Comparative ecomorphology and biogeography of Herpestidae and Viverridae (Carnivora). - In: Goswami, A. \& Friscia, A. (eds.), Carnivoran evolution: New views on phylogeny, form, and function: 246-268. Cambridge University Press, Cambridge.

Wozencraft, W. C. 1993: Carnivora. - In: Wilson, D. E. \& Reeder, D. (eds.), Mammal species of the world: a taxonomic and geographic reference, 2nd ed.: 279-348. Smithsonian Institution Press, Washington, D.C. 